\title{
Is the Improvement of CSR Helpful in Business Performance? Discussion of the Interference Effects of Financial Indicators from a Financial Perspective
}

\author{
Chih-Wei Lin $\left(\mathbb{D},{ }^{1}\right.$ Wei Peng Tan $\mathbb{I D}^{2}$, Su-Shiang Lee $\mathbb{D}^{1},{ }^{1}$ and Tso-Yen Mao $\mathbb{D}^{1}$ \\ ${ }^{1}$ Department of Leisure Services Management, Chaoyang University of Technology, Taichung, Taiwan \\ ${ }^{2}$ Department of Business Administration, Chaoyang University of Technology, Taichung, Taiwan \\ Correspondence should be addressed to Tso-Yen Mao; tymao.research@gmail.com
}

Received 5 April 2021; Revised 18 July 2021; Accepted 12 October 2021; Published 10 November 2021

Academic Editor: Baogui Xin

Copyright (C) 2021 Chih-Wei Lin et al. This is an open access article distributed under the Creative Commons Attribution License, which permits unrestricted use, distribution, and reproduction in any medium, provided the original work is properly cited.

\begin{abstract}
To achieve sustainable business operations, corporate betting on the implementation of social responsibility has become a trend of global concern. Therefore, companies that pay attention to and invest many resources in corporate social responsibility (CSR) have gradually become critical strategies for business operations. This strategy has a substantial effect on business performance, especially regarding the financial impact. This study aims to explore the effect of CSR improvement on financial performance, return on assets (ROA), return on equity (ROE), size, debt ratio, and asset turnover on its interference. A total of 346 items of data from Taiwan companies that have won the "CommonWealth Corporate Citizenship Award" from 2012 to 2018 were analyzed via descriptive statistics and hierarchical regression methods to determine the influence and adjustment of various factors layer by layer. CSR, firm size, debt ratio, and asset turnover have a significant prediction on ROA. CSR, firm size, and turnover have a significant prediction on ROE. Firm size and debt ratio have a significant negative moderation effect on CSR to ROA. The debt ratio has a significant negative moderation effect on CSR to ROE. This study concludes that CSR has a significant impact on business performance. CSR affects ROA moderated by firm size and ROA and ROE moderated by debt ratio. This study puts forward practical and future research suggestions for the relevant units to promote CSR development.
\end{abstract}

\section{Introduction}

Social attention on corporate social responsibility (CSR) has gradually shifted from developed countries to developing countries in recent years. Society hopes that multinational companies and local companies will be required to incorporate CSR as the business philosophy and value of the company. Porter and Kramer argue that corporations and society's mutual dependence implies that both business decisions and social policies must follow the principle of shared value, with choices benefiting both sides. Even though heightened corporate attention to CSR has not been entirely voluntary [1], the companies need to readjust their attitude towards CSR to improve their corporate image, gain reputation, and increase their profits. CSR has become an outstanding science, highly valued by academics, practical circles, and government units. Today, countries worldwide advocate the sustainable development goals (SDGs) as set by the United Nations at the 2015 Earth Summit Rio, Brazil. Then, according to a report from Better Business, Better World (BSDC) in 2017, it is estimated that, by 2030, there will be at least 12 trillion US dollars in annual global revenue and 380 million employment opportunities related to the SDGs. The report results show that the implementation of the United Nations Global SDGs has become a global development trend and has also become the development trend of future business opportunities for enterprises. The CSR concept has become a relevant component of modern business and risk management, as it ensures the successful functionality of a company [2].

The new millennium brings a new uncertain environment into business, along with intense pressure in 
companies to improve and establish new company strategies that allow CSR, which has become one of the management strategies of most enterprises, not only to increase market participation and obtain a significant level of company performance but also to survive in a market that gets more globalized and competitive by time [3], and it has also become the central axis of the long-term development of enterprises. Newman et al., using a representative sample of more than 5,000 Vietnamese enterprises to explore the firmlevel productivity effects of CSR, showed that CSR behavior might bring rewards [4]. However, it is undeniable that CSR is already a necessary task for modern enterprise management.

According to Carroll, the concept of CSR began to be mentioned at least as early as the 1930s [5]. CSR has gradually become more critical as the years change, and its definitions have become more diverse [6]. Taiwan CommonWealth Magazine established the Corporate Citizenship Index in 2007 and began conducting "Corporate Citizenship" surveys. It refers to the United Nations Program, the OECD, the US Dow Jones Index, and other international indicators and evaluation methods and divides the measurement of CSR into four facets: corporate governance, corporate commitment, social participation, and environmental sustainability. Corporate governance mainly measures the independence of the internal board of directors and the transparency of corporate information disclosure. Enterprise commitment refers to the company's commitment to the consumers, the care and training of its employees, and its investment in innovation and research and development. Social participation mainly measures whether the company has long-term investment or involvement in specific social issues and positive influences. Environmental sustainability involves investigating whether companies have adopted specific goals and methods in environmental protection and energy conservation management [7].

Financial performance is one of the methods to calculate business performance; the most commonly used indicators are return on assets (ROA), return on equity (ROE), or other indicators that measure the performance of a company's market value [8]. Dewi and Monalisa investigated the relationship between CSR, ROA, and ROE [9]. This study tries to use financial performance to measure business performance and aims to determine the impact of CSR on business performance through financial indicators. Based on the empirical evidence of previous studies, this study found that most of the financial performance measures of the studies were measured on basic accountancy. Therefore, this study selects the most commonly represented financial performance indicators of the company's operating performance as the indicators of business performance, which are ROA and ROE. In past research, there have been many demonstrations of the relationship between CSR and business performance. Patel and Misra obtained 340 responses from senior executives/managers working in multinational firms and found that CSR influences organizational performance when exercised towards external stakeholders [10]. The relationship between CSR and business performance will vary with research perspectives or measurement methods. The research of Hasan et al. demonstrated that the link between corporate operating performance and CSR would be affected by other regulatory factors [11]. Chatterjee and Wernerfelt's study indicates that the firm size will impact its strategic form. The larger the size of an enterprise is, the easier it is to raise funds. The size of an enterprise will affect its financing, which affects its operating performance [12]. The firm size is directly proportional to CSR. The larger the enterprise, the higher the CSR index [13]. McWilliams and Siegel's research proves that the debt ratio will affect the performance of CSR on the business performance of enterprises [14]. McGuire, Sundgren, and Schneeweis pointed out that the impact of asset turnover on business performance means that the company is operating well and represents an efficient use of resources [15]. Shen and Chang indicated that the better the asset turnover, the better the resources and operating conditions of the business [16]. From the research above, ROA and ROE are the effects of critical financial indicators that were discussed. Size of an enterprise, debt ratio, and asset turnover have a moderating effect on the impact of CSR on business performance. Therefore, this study explores the influence of enhancing CSR on ROA and ROE by moderating firm size, debt ratio, and turnover.

CSR is like a chameleon that changes its color according to its context [17]. In summary, CSR has become a global enterprises consensus and an indispensable condition for corporate growth or stability. The CSR would affect business performance, and business performance is an indicator of corporate effectiveness, which can assist companies in determining whether the adopted strategies, organizational structure, execution ability, and effectiveness allow them to reach the preset goals or help them to develop inspection targets for higher goals [18]. This study hopes that exploring CSR can help companies improve business performance, and, through the implementation of CSR, they can achieve the joint development of enterprises and society. ROA and ROE measure the business performance in the above study. At the same time, to make the analysis results more convincing, this study takes firm size, debt ratio, and turnover as the adjustment variables. The specific research objectives of this study are as follows:

(1) To investigate the impact of CSR, firm size, debt ratio, and turnover on ROA and ROE

(2) To investigate the impact of CSR on ROA and ROE regulated by firm size, debt ratio, and turnover

\section{Materials and Methods}

2.1. Research Framework. This study mainly explores the relationship between CSR and business performance. This study uses two financial indicators, ROA and ROE, as contingency terms. CSR is an independent variable, while firm size, debt ratio, and turnover rate are the adjustment variables. The research framework constructed is shown in Figure 1.

2.2. Research Subject. This study used Taiwan as an area of research. The Corporate Citizenship Index from Taiwan CommonWealth Magazine is one of Taiwan's most 


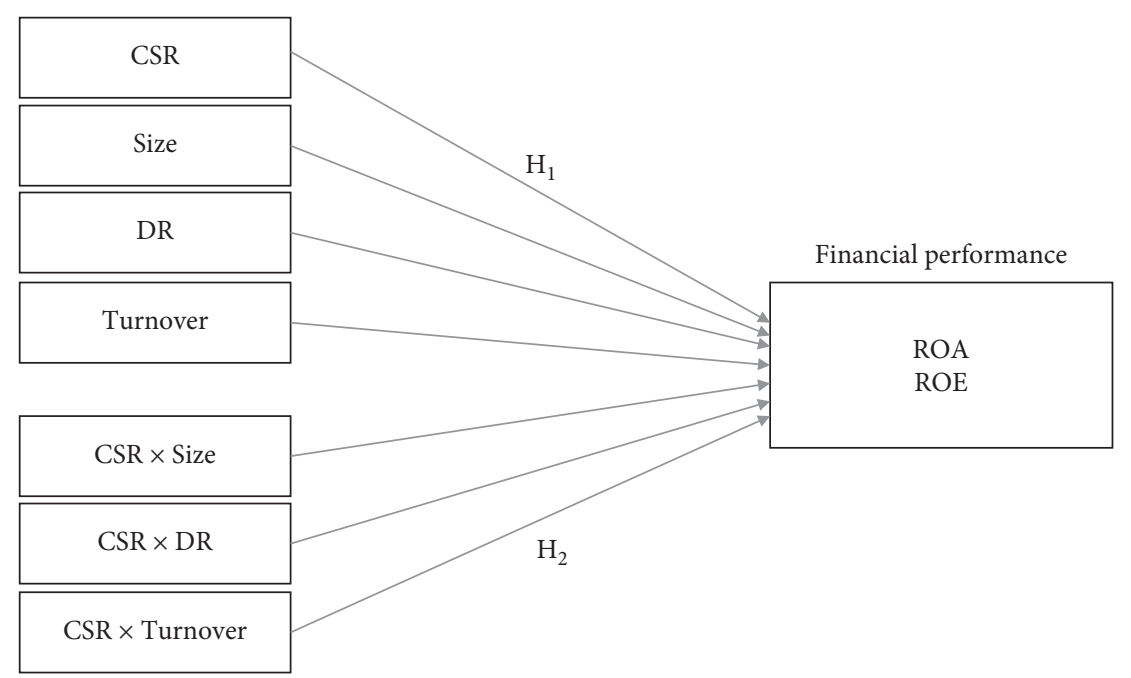

FIGURE 1: Research framework of CSR on ROA and ROE. CSR: corporate social responsibility; DR: debt ratio; ROA: return on assets; ROE: return on equity; $\mathrm{H}_{1}$ : hypothesis $1 ; \mathrm{H}_{2}$ : hypothesis 2 .

representative corporate social responsibility awards. The research object of this study was the enterprises that have won the CommonWealth Corporate Citizenship Award as the research sample. Taiwan CommonWealth Magazine was founded on June 1, 1981, and mainly reports news about Taiwan's economy and finance, business operations, and industry trends. It regularly launches surveys on corporate areas and people's livelihoods, including the Corporate Citizenship Index.

The survey and evaluation of the CommonWealth Magazine were divided into three stages. More than 2,000 recommended publicly issued companies and foreign companies were evaluated through expert review to 30 selected large-scale companies with revenues exceeding 10 billion, ten backbone enterprises with revenues below 10 billion, and ten foreign companies ranking the best corporate citizens in Taiwan.

In the first stage, companies from the public offering companies supervised by the Taiwan Financial Supervisory Commission (FSC) that have made profits for three consecutive years are selected. The Taiwanese foreign investors recommended by experts and scholars were invited to participate in the survey. In the second stage, a total of 118 short-listed companies were selected: 54 large-scale enterprises, 27 medium-scale enterprises, and 37 foreign-funded enterprises. In the third stage, judging, comprising twelve judges with credibility and social prestige, decided the rank of top 50 corporate citizens. A total of 572 companies were selected from 2012 to 2018. 111 foreign and 80 small companies were deleted, and 381 were left for financial analysis.

The firm size, debt, and turnover sample was taken from the Taiwan Economic Journal (TEJ) database. This study uses TEj's IFRS financial statements as aggregated sample data. In order to make the data obtained by this research more convincing, this research adopts the IFRS financial statements compiled by TEJ as the sample data. Taiwan officially entered the first year of IFRS in 2012. Therefore, the sample period of this study is selected from 2012 to 2018, a total of 7 years. After screening this research data, 35 companies with uneven financial information were excluded, and the final sample observations totaled 346 . The diversity of samples that accorded with the emphasis of the research method did not cause the research results to be biased due to the concentration of the sample data attributes. The detailed description of measuring variables is shown in Table 1.

\subsection{Research Tool and Analysis}

2.3.1. Operational Definition and Variable Measurement. The SPSS 18.0 statistical software was used in this study to analyze the data, and then mainly descriptive statistics were used to analyze the current situation and hierarchical regression analysis to discuss the impact of each factor layer by layer. ROA and ROE act as dependent variables, while CSR acts as an independent variable, and firm size, debt ratio, and turnover act as the adjustment variables to identify the impact of CSR on business performance. The measurements of CSR, firm size, debt ratio, and turnover were obtained from the evaluation data of the CommonWealth Corporate Citizenship Award, and each piece of sample data was obtained from the TEJ financial database. CSR is divided into four dimensions: corporate governance, corporate commitment, social participation, and environmental sustainability. The scores of each dimension account for $25 \%$, and the total score is up to 10 points. The scale of enterprises is divided into large and medium enterprises, the debt ratio is debt divided by total assets, and the turnover is net operating income divided by average total assets. The significance level was set at $\alpha=0.05$.

2.3.2. Empirical Model. This study mainly investigated the relationship between the independent variable CSR and the dependent variable business performance. This study used 
TABLE 1: Measuring variables.

\begin{tabular}{lc}
\hline Variable & Measurement \\
\hline $\begin{array}{l}\text { Dependent variables } \\
\text { ROA }\end{array}$ & $\begin{array}{c}\text { Net income/total assets } \\
\text { ROE }\end{array}$ \\
\hline $\begin{array}{l}\text { Independent variable } \\
\text { CSR }\end{array}$ & Net income/average shareholders' equity \\
\hline $\begin{array}{l}\text { Moderating variables } \\
\text { Size }\end{array}$ & Index of Common Wealth Corporate Citizenship Award \\
$\begin{array}{l}\text { Debt ratio } \\
\text { Turnover }\end{array}$ & Large enterprises $=1$; medium enterprises $=0$ \\
& Total debt/total assets \\
\end{tabular}

Regression Model 1 to test whether CSR significantly impacts ROA and Regression Model 2 to test whether CSR significantly impacts ROE. The regression equation of this study is divided into two sections. The first section is the regression formula without the interaction term, and the second section is the regression formula with the interaction term.

The first section is

$$
\begin{aligned}
\mathrm{ROA}_{i} & =\beta_{0}+\beta_{1} \mathrm{CSR}_{i}+\beta_{2} \mathrm{SIZE}_{i}+\beta_{3} \mathrm{DR}_{i}+\beta_{4} \mathrm{TURNOVER}_{i}+\varepsilon_{i}, \\
\mathrm{ROE}_{i} & =\beta_{0}+\beta_{1} \mathrm{CSR}_{i}+\beta_{2} \mathrm{SIZE}_{i}+\beta_{3} \mathrm{DR}_{i}+\beta_{4} \mathrm{TURNOVER}_{i}+\varepsilon_{i} .
\end{aligned}
$$

The second section is

$$
\begin{aligned}
\mathrm{ROA}_{i}= & \beta_{0}+\beta_{1} \mathrm{CSR}_{i}+\beta_{2} \mathrm{SIZE}_{i}+\beta_{3} \mathrm{DR}_{i}+\beta_{4} \mathrm{TURNOVER}_{i}+\beta_{12} \mathrm{CSR}_{i} \times \mathrm{SIZE}_{i}+\beta_{13} \mathrm{CSR}_{i} \times \mathrm{DR}_{i}+\beta_{14} \mathrm{CSR}_{i} \\
& \times \mathrm{TURNOVER}_{i}+\varepsilon_{i}, \\
\mathrm{ROE}_{i}= & \beta_{0}+\beta_{1} \mathrm{CSR}_{i}+\beta_{2} \mathrm{SIZE}_{i}+\beta_{3} \mathrm{DR}_{i}+\beta_{4} \mathrm{TURNOVER}_{i}+\beta_{12} \mathrm{CSR}_{i} \times \mathrm{SIZE}_{i}+\beta_{13} \mathrm{CSR}_{i} \times \mathrm{DR}_{i}+\beta_{14} \mathrm{CSR}_{i} \\
& \times \mathrm{TURNOVER}_{i}+\varepsilon_{i} .
\end{aligned}
$$

\section{Results}

3.1. Current Analysis of Research Variables. This section mainly analyzes via descriptive statistics to understand the distribution. The analysis results in Table 2 show that, based on the samples used in this research, all the companies have won the CommonWealth Corporate Citizenship Award; the maximum CSR score sample is 9.50, and the minimum is 7.17. The overall CSR score is high. The debt ratio in the sample shows an extensive range. The maximum value is 96.78 , the minimum value is 6.43 , and the average is 53.41 . It means that companies with CSR are not necessarily low in debt ratio, and most have won the Corporate Citizenship Award; hence, it can be seen that the debt ratio shows a middle-to-upward trend. The maximum value of the turnover is 3.01 , and the minimum value is 0.18 , which indicates that the turnover of the winning companies has remained below 3.01. The maximum value of ROA in the sample is 33.22 , and the minimum value is -13.95 , indicating that companies performing CSR may not have higher ROA and companies with negative ROA may not perform well in CSR. The maximum ROE in the sample is 67.78, and the minimum value is -23.49 , which indicates that the ROE level does not indicate that the implementation of CSR is not exemplary.
Through Pearson's correlational analysis in Table 2, it is revealed that the correlation between debt ratio and ROA is as high as $-.54(p<0.05)$, indicating that there is a significant negative correlation between debt ratio and ROA. The correlation between turnover and ROA is as high as $-.20(p<0.05)$, indicating a significant negative correlation between turnover and ROA. Besides, the scale of an enterprise is a dichotomous variable, and the scale-related correlation coefficient is the twopoint series correlation. Based on the above, it can be known that the company debt ratio that implements CSR may not be low. The ROA and ROE may also show negative numbers.

3.2. The Impact of CSR on ROA. From Table 3, the first section variable has a significant explanatory power on the dependent variable, $R^{2}=0.34, F(4,341)=44.32$, and $p<0.05$. The ROA is representing the performance of the enterprise. ROA is affected by four variables, which account for $34.2 \%$ of the variation in the strain term. Among the four variables, CSR contributed the most $(\beta=0.19, t(341)=4.11, p<0.05)$, followed by turnover $(\beta=0.18, t(341)=3.93, p<0.05)$, firm size $(\beta=-0.11, t(341)=2.37, \quad p<0.05)$, and debt ratio $(\beta=-0.48, t(341)=-10.33, p<0.05)$. It shows that CSR and turnover mainly create the contribution of the first section. Through the standardized regression coefficient $(\beta)$, CSR 
TABLe 2: Descriptive statistics for each variable.

\begin{tabular}{|c|c|c|c|c|c|c|}
\hline \multicolumn{4}{|c|}{ Descriptive statistics } & \multicolumn{3}{|c|}{ Correlation coefficient } \\
\hline Variable & Mean & SD & Minimum & Maximum & $\mathrm{ROA}$ & $\mathrm{ROE}$ \\
\hline CSR & 8.33 & 0.46 & 7.17 & 9.50 & $-0.14^{* *}$ & $-0.10^{* *}$ \\
\hline DR & 53.41 & 22.54 & 6.43 & 96.78 & $-0.54^{*}$ & $-0.15^{*}$ \\
\hline TURNOVER & 0.84 & 0.62 & 0.18 & 3.01 & $-0.20^{*}$ & $-0.19^{*}$ \\
\hline ROA & 5.97 & 5.95 & -13.95 & 33.22 & & \\
\hline ROE & 12.14 & 9.98 & -23.49 & 67.78 & & \\
\hline
\end{tabular}

${ }^{*} p<0.05$.

TABLE 3: Hierarchical regression model of ROA.

\begin{tabular}{|c|c|c|c|c|c|c|c|c|}
\hline \multicolumn{2}{|c|}{ Module internal variable } & \multicolumn{3}{|c|}{ First section } & \multicolumn{3}{|c|}{ Second section } & \multirow{2}{*}{ VIF } \\
\hline 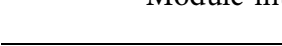 & vantavie & $\beta$ & $t$ & $p$ & B & $t$ & $p$ & \\
\hline \multirow{7}{*}{ Independent variable } & $\operatorname{CSR}(\mathrm{A})$ & 0.19 & $4.11^{*}$ & 0.001 & 0.38 & $4.00^{*}$ & 0.001 & 4.70 \\
\hline & SIZE (B) & -0.11 & $-2.37^{*}$ & 0.018 & -0.15 & $-3.07^{*}$ & 0.002 & 1.24 \\
\hline & DEPT RATIO (C) & -0.48 & $-10.33^{*}$ & 0.001 & -0.46 & $-9.92^{*}$ & 0.001 & 1.17 \\
\hline & TURNOVER (D) & 0.18 & $3.93^{*}$ & 0.001 & 0.14 & $2.98^{*}$ & 0.003 & 1.25 \\
\hline & $(\mathrm{A}) \times(\mathrm{B})$ & & & & -0.23 & $-2.46^{*}$ & 0.014 & 4.49 \\
\hline & $(\mathrm{A}) \times(\mathrm{C})$ & & & & -0.11 & $-2.33^{*}$ & 0.021 & 1.15 \\
\hline & $(\mathrm{A}) \times(\mathrm{D})$ & & & & -0.06 & $-1.13^{*}$ & 0.259 & 1.26 \\
\hline Model summary & $\left(R^{2}, \mathrm{~F}, \Delta R^{2}\right)$ & \multicolumn{3}{|c|}{$0\left(0.34,44.32^{*}, 0.34^{*}\right)$} & \multicolumn{3}{|c|}{$\left(0.37,28.19^{*}, 0.03^{*}\right)$} & \\
\hline
\end{tabular}

${ }^{*} p<0.05$. CSR: corporate social responsibility; $\beta$ : path coefficients; $t$ : $t$-test; VIF: variance inflation factor.

and turnover positively impact ROA, while the firm size and debt ratio have a negative impact on ROA. The following is the standard regression model for overall fit:

$$
\begin{aligned}
\mathrm{ROA}= & 19 * \mathrm{CSR}-0.11 * \mathrm{SIZE}-0.48 * \mathrm{DR} \\
& +0.18 * \text { TURNOVER. }
\end{aligned}
$$

In the second section, after the interaction terms of CSR and various variables were put into the model, the explanatory power of the model reached $R^{2}=0.37, F(7,338)=$ $28.19(p<0.05)$. Zone explanatory power increase was $R^{2}=0.027, F$ change $(3,338)=4.74 \quad(p<0.05)$, and the increment of the display section is statistically significant. The three interaction terms are "CSR $\times$ turnover" $(\beta=-0.06$, $t(338)=-1.136, p=0.26)$, “CSR $\times$ debt ratio" $(\beta=-0.11, t$ $(338)=-2.33, p<0.05)$, and “CSR $\times$ firm size" $(\beta=-0.23, t$ $(338)=-2.5, p<0.05)$. Through the standardized regression coefficient $(\beta)$, the interaction term between CSR and debt ratio has a negative impact on ROA, the interaction term between CSR and firm size has a negative impact on ROE, and the interaction term between CSR and turnover has no significant effect on ROA. The following is the standard regression model for overall fit:

$$
\begin{aligned}
\mathrm{ROA}= & 38 * \mathrm{CSR}-.15 * \mathrm{SIZE}-.46 * \mathrm{DR}+.14 * \mathrm{TURNOVER}-0.23 * \mathrm{CSR} * \mathrm{SIZE} \\
& -0.11 * \mathrm{CSR} * \mathrm{DR}+0.06 * \mathrm{CSR} * \mathrm{TURNOVER} .
\end{aligned}
$$

3.3. The Impact of CSR on ROE. From Table 4, the first section variable has significant explanatory power on the dependent variable, $R^{2}=0.08, F(4,341)=7.44, p<0.05$. The $\mathrm{ROE}$ is representing the performance of an enterprise. ROE is affected by four variables, which account for $8.0 \%$ of the variation in the strain term. Among the four variables, turnover contributed the most $(\beta=0.23, t(341)=4.12$, $p<0.05)$, followed by CSR $(\beta=0.17, t(341)=3.02, p<0.05)$ and, last, firm size $(\beta=-0.12, t(341)=-2.14, p<0.05)$. It shows that the contribution of the first section is mainly created by turnover and CSR. Through the standardized regression coefficient $(\beta)$, the turnover and CSR positively impact ROE, the firm size has a negative impact on ROE, and the debt ratio has no significant impact on ROE. The following is the standard regression model for overall fit:

$$
\mathrm{ROE}=0.17 * \mathrm{CSR}-0.12 * \mathrm{SIZE}-0.08 * \mathrm{DR}+0.23 * \text { TURNOVER }
$$

In the second section, after the interaction terms of CSR and various variables were put into the model, the explanatory power of the model reached $R^{2}=0.10, F$ $(7,338)=5.29(p<0.05)$. Zone explanatory power increase 
TABLE 4: Hierarchical regression model of ROE.

\begin{tabular}{|c|c|c|c|c|c|c|c|c|}
\hline \multicolumn{2}{|c|}{ Module internal variable } & \multicolumn{3}{|c|}{ First section } & \multicolumn{3}{|c|}{ Second section } & \multirow{2}{*}{ VIF } \\
\hline คทำ & & $\beta$ & $t$ & $p$ & $\beta$ & $t$ & $p$ & \\
\hline \multirow{7}{*}{ Independent variable } & $\operatorname{CSR}(\mathrm{A})$ & 0.17 & $3.02^{*}$ & 0.003 & 0.29 & $2.60^{*}$ & 0.010 & 4.70 \\
\hline & SIZE (B) & -0.12 & $-2.14^{*}$ & 0.033 & -0.15 & $-2.52^{*}$ & 0.012 & 1.24 \\
\hline & DEPT RATIO (C) & -0.08 & -1.43 & 0.153 & -0.06 & -1.07 & 0.285 & 1.17 \\
\hline & TURNOVER (D) & 0.23 & $4.12^{*}$ & 0.001 & 0.20 & $3.45^{*}$ & 0.001 & 1.25 \\
\hline & $(\mathrm{A}) \times(\mathrm{B})$ & & & & -0.15 & -1.39 & 0.166 & 4.49 \\
\hline & $(\mathrm{A}) \times(\mathrm{C})$ & & & & -0.11 & $-1.97^{*}$ & 0.049 & 1.15 \\
\hline & $(\mathrm{A}) \times(\mathrm{D})$ & & & & -0.03 & -0.56 & 0.574 & 1.26 \\
\hline Model summary & $\left(R^{2}, F, \Delta R^{2}\right)$ & \multicolumn{3}{|c|}{$\left(0.080,7.44^{*}, 0.08^{*}\right)$} & \multicolumn{4}{|c|}{$\left(0.10,5.29^{*}, 0.02\right)$} \\
\hline
\end{tabular}

${ }^{*} p<0.05$. CSR: corporate social responsibility; $\beta$ : path coefficients; $t$ : $t$-test; VIF: variance inflation factor.

was $R^{2}=0.018, F$ change $(3,338)=2.37(p=0.08)$, showing that the investment of the second section interaction term can effectively increase the interpretation of the model by an additional $1.8 \%$; that is, the section increment is statistically significant. The three interaction terms are "CSR $\times$ turnover" $(\beta=-0.03, t(338)=0.56, p=0.57)$, "CSR $\times$ debt ratio" $(\beta=-0.11, t(338)=-1.97, p<0.05)$, and "CSR $\times$ firm size" $(\beta=-0.15, t(338)=-1.39, p=0.17)$. Through the standardized regression coefficient $(\beta)$, the interaction term between CSR and debt ratio has a negative impact on ROE, and the other interaction term has no significant effect on ROE. The following is the standard regression model for overall fit:

$$
\begin{aligned}
\mathrm{ROE}= & .29 * \mathrm{CSR}-.15 * \mathrm{SIZE}-.06 * \mathrm{DR}+.20 * \mathrm{TURNOVER}-.15 * \mathrm{CSR} * \mathrm{SIZE} \\
& -.11 * \mathrm{CSSR} * \mathrm{DR}-.03 * \mathrm{CSR} * \mathrm{TURNOVER} .
\end{aligned}
$$

From Figure 2, the relationship between CSR and ROE is affected by adjusting the debt ratio. Then, according to the slope, it can be realized that low debt ratio enterprises will have a significant increase in ROE as CSR increases; that is, the lower the debt ratio is, the more effectively the relationship between CSR and ROE can be adjusted.

\section{Discussion}

This study draws a reference with the comparison analysis of adjustment analysis proposed by Jaccard and Turrisi to understand further the relationship of the explanatory power of the interaction term reaching a significant part [19]. From Figure 3, the relationship between CSR and ROA is affected by the adjustment of firm size. Then, according to the slope, it can be observed that medium-scale enterprises will have a significant increase in ROA as CSR increases; that is, the smaller the size of the enterprise, the better the relationship between CSR and ROA. Besides, the relationship between CSR and ROA is also affected by the adjustment of the debt ratio. According to the slope, it can be observed that the low debt ratio enterprise will increase the ROA as CSR increases (Figure 4); that is, the lower the debt ratio is, it can effectively adjust the relationship between CSR and ROA.

It can be seen that CSR and turnover are important influencing factors in business performance; the explanatory power is $34.2 \%$. When the interaction term is input, the district explanatory power is $36.9 \%$, and the input of the interaction term can effectively improve the model's extra $2.7 \%$ predictive power, indicating that the ROA has many critical influencing factors. This analysis's results show that
CSR will positively affect the ROA. The result is similar to the research results of scholars, such as from previous studies $[14,20,21]$. The ROA will change with the level of CSR; the higher the company performs CSR, the higher the result of ROA is.

Regarding the adjustment variables, the relationship between the firm size and the debt ratio with the ROA showed a significant and negative impact; the relationship between the turnover and the ROA showed a significant and positive impact. Then, through the interaction term, the relationship of the firm size and debt ratio between CSR and ROA will have a regulating effect. The result that the firm size will have an adjustment effect echoes the research point of Chatterjee and Wernerfelt [12]. In addition, the debt ratio will have an adjustment effect, which echoes the result of McWilliams and Siegel (2000) that the debt ratio will affect the company's business performance [14]. From Figure 3, it can be seen that the straight line of the medium-scale enterprises is significantly increased from the lower left to the upper right. Representing the medium-scale firm, the implementation of CSR has a better effect on ROA here than in the large-sized firm. Then, from Figure 4, it can be realized that companies with lower debt ratios have higher slopes than those with higher debt ratios, which indicates that CSR performance by companies with lower debt has a better effect on ROA than that by companies with higher debt ratios.

From Figure 2, the relationship between CSR and ROE is affected by adjusting the debt ratio. Then, according to the slope, it can be seen that low debt ratio enterprises will have a significant increase in ROE as CSR increases; that is, the 


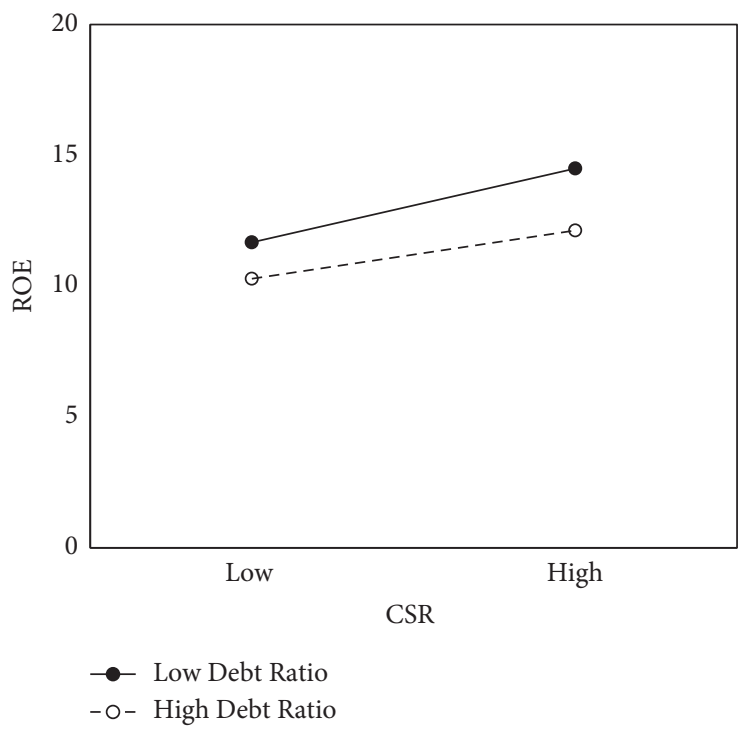

FIgURE 2: Cross diagram of CSR and debt ratio of ROE.

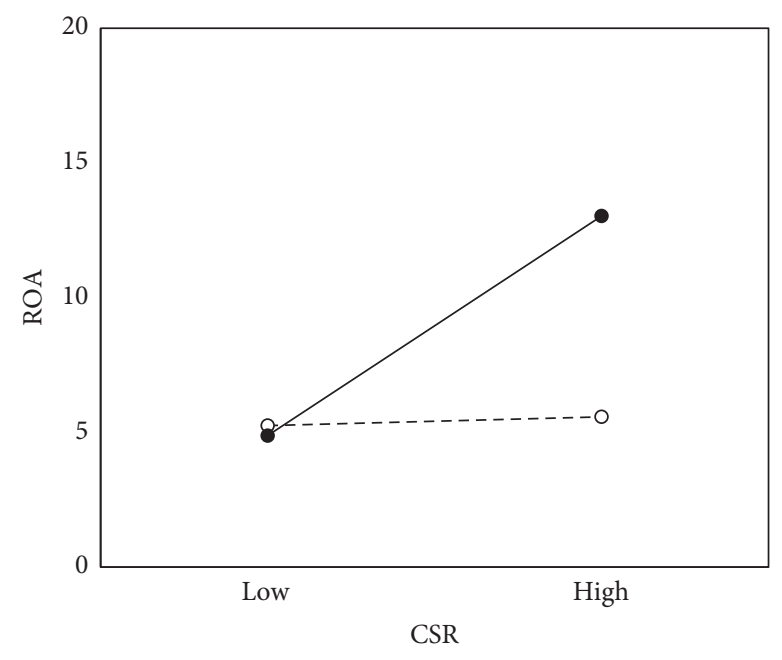

- - Medium size firm

-o- Large size firm

FIgURE 3: Cross diagram of CSR and size of ROA.

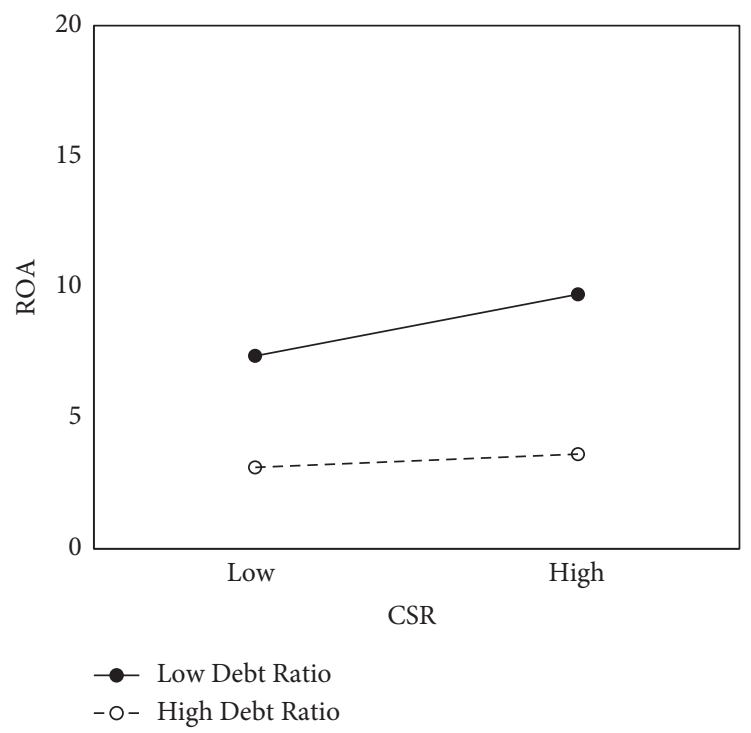

FIGURE 4: Cross diagram of CSR and debt ratio (DR) of ROA. 
lower the debt ratio is, the more effectively the relationship between CSR and ROE can be adjusted. It also can be noted that CSR and turnover are important influencing factors in business performance, where explanatory power is $8.0 \%$. When the interaction term is input, the district explanatory power is $9.9 \%$; the input of the interaction term can effectively improve the model's extra $1.8 \%$ predictive power, indicating that ROE has many critical influencing factors. This analysis's result shows that CSR will positively affect ROA. The result is similar to the research results of scholars such as Moskowitz, Bowman and Haire, Liu et al., and Nieh et al., who proved that ROE would change with the level of CSR $[22,23]$.

Regarding the adjustment variables, the relationship between the firm size and ROE showed a significant and negative impact, while the relationship between the turnover and the ROE showed a significant and positive impact. Then, through the interaction term, it can be found that the relationship of debt ratio between CSR and ROE will have a regulating effect. The result that the debt ratio will have an adjustment effect echoes the research point of Nakamura [24]. The research results of Nieh et al. further validate the analysis results of this study; that is, the debt ratio has a regulating effect between CSR and ROE [23]. From Figure 2, it can be noted that companies with lower debt ratios have higher slopes than those with higher debt ratios, which indicates that CSR performance by companies with lower debt ratios has a better effect on ROE than that by companies with higher debt ratios.

\section{Conclusions}

This study concluded that CSR has a significant impact on business performance, and firm size and debt ratio have a moderating effect on CSR. The hierarchical regression analysis found that CSR and turnover positively and significantly impact ROA, while the firm size and debt ratio have a negative and significant impact on ROA. This result shows that CSR is an essential factor that directly affects whether an enterprise makes full use of its assets. Furthermore, the hierarchical regression analysis found that CSR and turnover have a positive and significant impact on ROE, while firm size has a negative and significant impact on ROE, and the debt ratio did not reach a significant predictive power on ROE. This result shows that turnover has the most significant influence; it is an essential factor that directly affects the company's operating capacity and is essential for shareholders to measure whether it is worth continuing to invest. Enterprises should strive to improve the fulfillment of CSR. This research first suggests that companies should focus on the fulfillment of CSR regardless of the firm size, the level of the debt ratio, and whether the asset turnover rate is good or not. Enterprises still need to rely on social resources to achieve sustainable operations, take from society, and feedback to society to form an excellent cycle to avoid an imbalance between supply and demand.

Firm size has a significant negative regulatory effect on the impact of CSR on ROA. In verifying the adjustment effect, the results of this study show that the effect of firm size has a significant negative adjustment effect between CSR and ROA. The larger the firm's size, the weaker the relationship between CSR and ROA. The medium-scale firm can enhance the effectiveness of its ROA by enhancing CSR. Based on the research results, this research suggests that the medium-scale firm should implement more CSR to help to increase the ROA. The empirical evidence of this research proves that low-scale enterprises will have a substantial increase in the ROA as CSR. Then, the large companies still show an upward trend in the relationship between CSR and ROA.

In verifying the adjustment effect, the results of this study show that the effect of debt ratio has a significant negative adjustment effect between CSR and ROA. That is, the larger the debt ratio, the weaker the relationship between CSR and ROA. The debt ratio has a significant negative regulatory effect on the impact of CSR on ROE. This result shows that the debt ratio has a significant negative adjustment effect between CSR and ROE in verifying the adjustment effect. That is, the larger the debt ratio, the weaker the relationship between CSR and ROE. This research is expected to analyze the impact of CSR on business performance and explore how companies can further help corporate growth through CSR. The empirical results prove that the promotion of CSR will have an impact on business performance. In addition, the empirical results show that firm size and debt ratio have a regulating effect on the relationship between CSR and ROA. The debt ratio has a regulating effect on the return on the relationship between CSR and ROE. Enterprises should pay attention to the influence of the debt ratio when implementing CSR. According to the research results, the relationship between CSR and ROA is affected by the debt ratio adjustment. Therefore, this research suggests that companies should pay attention to controlling the corporate debt ratio when fulfilling CSR. If the debt ratio is too high, it will affect the use of corporate funds and thus affect corporate profitability.

\section{Data Availability}

All data generated or analysed during the study are included in this published article.

\section{Conflicts of Interest}

The authors declare that they have no conflicts of interest.

\section{Authors' Contributions}

Su-Shiang Lee and Chih-Wei Lin were responsible for conceptualization of the study, Wei-Peng Tan and Chih-Wei Lin were responsible for methodology, Wei-Peng Tan and Chih-Wei Lin developed the software, Su-Shiang Lee and Tso-Yen Mao validated the study, Wei-Peng Tan and ChihWei Lin performed formal analysis, Wei-Peng Tan and Chih-Wei Lin were involved in investigation, Wei-Peng Tan and Chih-Wei Lin wrote the original draft, Tso-Yen Mao and Chih-Wei Lin reviewed and edited the article, and Su- 
Shiang Lee supervised the study. All authors have read and agreed to the published version of the manuscript.

\section{References}

[1] M. E. Porter and M. R. Kramer, "Strategy and society: the link between competitive advantage and corporate social responsibility," Harvard Business Review, vol. 84, no. 12, pp. 78-163, 2006.

[2] G. Barauskaite and D. Streimikiene, "Corporate social responsibility and financial performance of companies: the puzzle of concepts, definitions and assessment methods," Corporate Social Responsibility and Environmental Management, vol. 28, no. 1, pp. 278-287, 2021.

[3] G. M. Guzman, S. Y. P. Castro, and G. C. L. Torres, "Corporate social responsibility and business performance: the role of Mexican SMEs," International Journal of Asian Social Science, vol. 6, no. 10, pp. 568-579, 2016.

[4] C. Newman, J. Rand, F. Tarp, and N. Trifkovic, "Corporate social responsibility in a competitive business environment," Journal of Development Studies, vol. 56, no. 8, pp. 1455-1472, 2020.

[5] A. B. Carroll, "Corporate social responsibility," Business \& Society, vol. 38, no. 3, pp. 268-295, 1999.

[6] A. Dahlsrud, "How corporate social responsibility is defined: an analysis of 37 definitions," Corporate Social Responsibility and Environmental Management, vol. 15, no. 1, pp. 1-13, 2008.

[7] T. C. Magazine, 2018, https://topic.cw.com.tw/csr/report_EN. aspx.

[8] P. L. Cochran and R. A. Wood, "Corporate social responsibility and financial performance," Academy of Management Journal, vol. 27, no. 1, pp. 42-56, 1984.

[9] K. Dewi and M. Monalisa, "Effect of corporate social responsibility disclosure on financial performance with audit quality as a moderating variable," Binus Business Review, vol. 7, no. 2, pp. 149-155, 2016.

[10] K. S. Patel and M. Misra, "Linking corporate social responsibility (CSR) and organizational performance: the moderating effect of corporate," European Research on Management and Business Economics, vol. 27, no. 1, pp. 60-64, 2021.

[11] I. Hasan, N. Kobeissi, L. Liu, and H. Wang, "Corporate social responsibility and firm financial performance: the mediating role of productivity," Journal of Business Ethics, vol. 149, no. 3 , pp. 671-688, 2018.

[12] S. Chatterjee and B. Wernerfelt, "The link between resources and type of diversification: theory and evidence," Strategic Management Journal, vol. 12, no. 1, pp. 33-48, 1991.

[13] C.-H. Huang, H.-K. Peng, H.-W. Chung, and T. Chang, "Evaluation of China's top 100 corporate social responsibility development," China's Industrial Economy, vol. 10, pp. 23-35, 2009.

[14] A. McWilliams and D. Siegel, "Corporate social responsibility and financial performance: correlation or misspecification?" Strategic Management Journal, vol. 21, no. 5, pp. 603-609, 2000.

[15] J. B. McGuire, A. Sundgren, and T. Schneeweis, "Corporate social responsibility and firm financial performance," Academy of Management Journal, vol. 31, no. 4, pp. 854-872, 1988.

[16] C.-H. Shen and Y. Chang, "Does corporate social responsibility improve financial performance? Evidence from Ftse4good UK index. [Does corporate social responsibility improve financial performance? Evidence from Ftse4good UK index]," Academia Economic Papers, vol. 36, no. 3, pp. 339-385, 2008.
[17] N. Mitra, "Impact of strategic management, corporate social responsibility on firm performance in the post mandate period: evidence from India," International Journal of Corporate Social Responsibility, vol. 6, no. 1, pp. 1-15, 2021.

[18] M. W. Grady, "Performance measurement: implementing strategy," Strategic Finance, vol. 72, no. 12, p. 49, 1991.

[19] J. Jaccard, R. Turrisi, and J. Jaccard, Interaction Effects in Multiple Regression, Sage, Newbury Park, CA, USA, 2003.

[20] S. A. Waddock and S. B. Graves, "The corporate social performance-financial performance link," Strategic Management Journal, vol. 18, no. 4, pp. 303-319, 1997.

[21] R. E. Wokutch and B. A. Spencer, "Corporate saints and sinners: the effects of philanthropic and illegal activity on organizational performance," California Management Review, vol. 29, no. 2, pp. 62-77, 1987.

[22] E. H. Bowman and M. Haire, "A strategic posture toward corporate social responsibility," California Management Review, vol. 18, no. 2, pp. 49-58, 1975.

[23] C.-C. Nieh, T.-M. Lin, and C. Chi, "The impact of corporate sizes on the effect of corporate social responsibility on corporate financial performance. [The impact of corporate sizes on the effect of corporate social responsibility on corporate financial performance]," Taiwan Journal of International Business Studies, vol. 11, no. 1, pp. 39-58, 2017.

[24] L. I. Nakamura, What is the US Gross Investment in Intangibles?:(at Least) One Trillion Dollars a Year!, Economic Research Division, Federal Reserve Bank of Philadelphia, Philadelphia, PA, USA, 2001. 